\title{
Examples of deformation-dependent flow simulations of conjunctive use with MF-OWHM
}

\author{
R. T. Hanson, J. Traum, S. E. Boyce, W. Schmid, and J. D. Hughes \\ U.S. Geological Survey, 4165 Spruance Rd. Suite 200, San Diego, CA 92101, USA \\ Correspondence to: R. T. Hanson (rthanson@usgs.gov) \\ Published: 12 November 2015
}

\begin{abstract}
The dependency of surface- and groundwater flows and aquifer hydraulic properties on deformation induced by changes in aquifer head is not accounted for in the standard version of MODFLOW. A new USGS integrated hydrologic model, MODFLOW-OWHM, incorporates this dependency by linking subsidence and mesh deformation with changes in aquifer transmissivity and storage coefficient, and with flows that also depend on aquifer characteristics and land-surface geometry. This new deformation-dependent approach is being used for the further development of the integrated Central Valley hydrologic model (CVHM) in California. Preliminary results from this application and from hypothetical test cases of similar systems show that changes in canal flows, stream seepage, and evapotranspiration from groundwater $\left(\mathrm{ET}_{\mathrm{gw}}\right)$ are sensitive to deformation. Deformation feedback has been shown to also have an indirect effect on conjunctive surface- and groundwater use components with increased stream seepage and streamflows influencing surface-water deliveries and return flows. In the Central Valley model, land subsidence may significantly degrade the ability of the major canals to deliver surface water from the Delta to the San Joaquin and Tulare basins. Subsidence can also affect irrigation demand and $\mathrm{ET}_{\mathrm{gw}}$, which, along with altered surface-water supplies, causes a feedback response resulting in changed estimates of groundwater pumping for irrigation. This modeling feature also may improve the impact assessment of dewatering-induced land subsidence/uplift (following irrigation pumping or coal-seam gas extraction) on surface receptors, inter-basin transfers, and surface infrastructure integrity.
\end{abstract}

\section{Introduction and background}

With conjunctive use of surface water and groundwater, excessive groundwater withdrawals in alluvial aquifers can lead to a physical reconfiguration of hydrostratigraphy, aquifer properties, surface infrastructure, and conjunctive water-use management owing to the effects of land subsidence. This has occurred in many of the major alluvial aquifers throughout the world. For example, in California's Central Valley, groundwater pumping resulting from the growing irrigation demand has led to significant land subsidence in the areas of the western San Joaquin Valley (Faunt et al., 2009, 2011) and, to the south, in the Tulare Basin, where historical declines in groundwater levels were greatest and are predicted to continue with climate change (Hanson et al., 2012). Subsidence and differential subsidence also are affecting the integrity and efficiency of the Delta Mendota Canal and Cali- fornia Aqueduct along the west side of the valley (Sneed et al., 2013).

Conjunctive use is the combined use of surface water and groundwater (UNESCO, 2010). The evolution of conjunctive-use management has come to include a framework of both natural and anthropogenic components of surface water and groundwater resources. The engineered components of supply and demand have become more sophisticated and ubiquitous in the urban and agricultural landscape. Many of these components such as canal operation, pumping of multiple-aquifer wells, aquifer storage and recovery, and reuse have an effect on conjunctive-use strategies. The connection to potential land subsidence has not been systemically linked to key processes and hydraulic properties of groundwater flow in order to understand the effects on conjunctive use. The feedback from these and other components that are linked to conjunctive use may require combined as- 

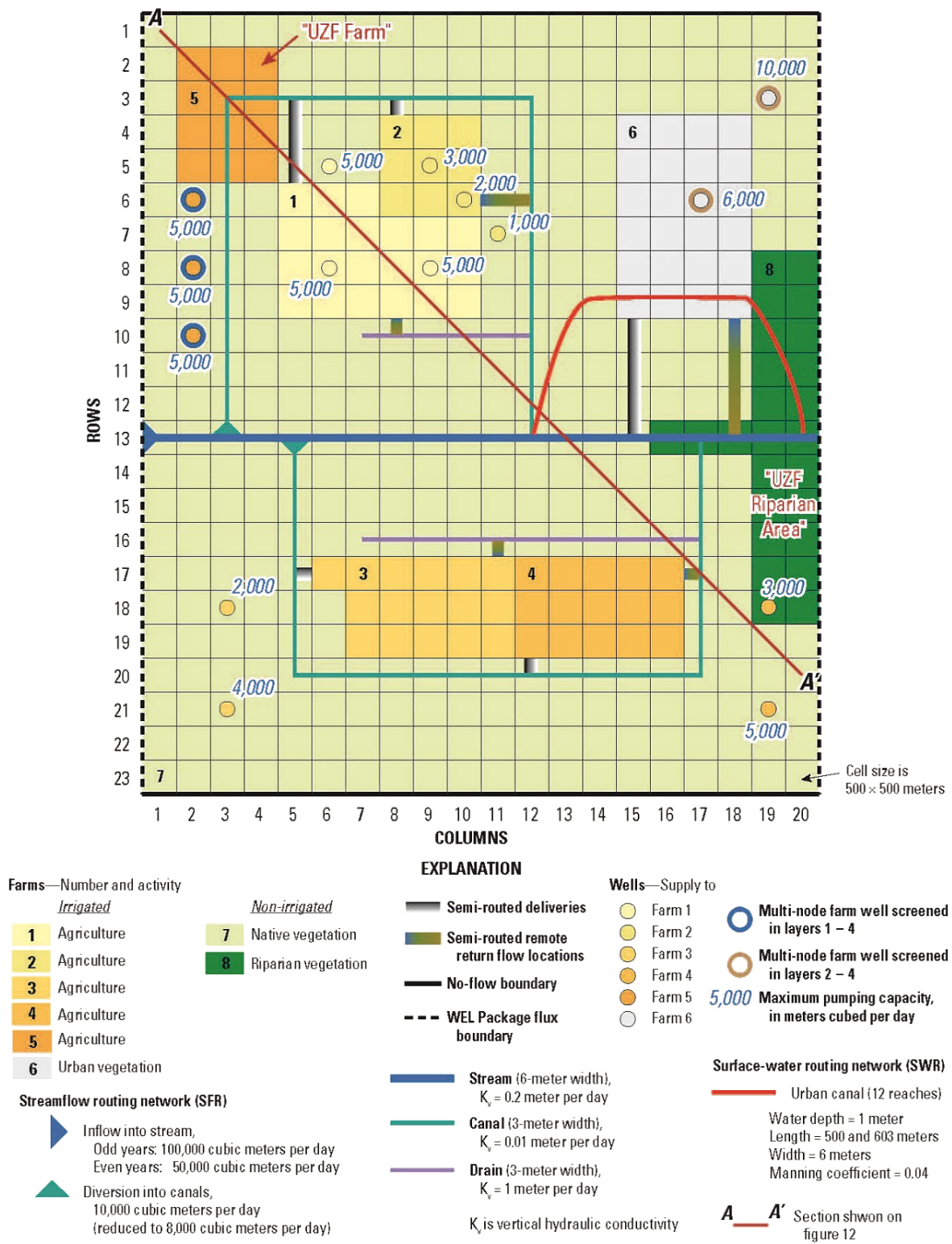

Figure 1. Plan view of model domain, grid resolution, boundary conditions, distribution of farms and farm wells, and streamflow routing network with points of diversion to farms and points of return flow from farms and surface-water canal traversing urban area (Schmid et al., 2014).

sessment within an integrated physically-based and supplyand-demand modeling structure.

Linking the effects of subsidence to changes in aquifer properties and other components of the hydrologic landscape is critical to conjunctive-use management. This type of analysis helps to identify and quantify the flow capacities and limits that these components can bring to conjunctive use. Flow capacities and limits may depend on aquifer head, other flow components, or deformation, and, hence, cannot be directly quantified through simple water allocation models. One of the current issues for regions within which large amounts of surface water are transported via canal sys- tems is the potential effects on infrastructure from land subsidence. In particular, reduced surface-water supplies owing to dry climate and environmental constraints are being offset by additional groundwater pumpage that can cause additional land subsidence. The feedback from this cause-andeffect linkage within a conjunctive-use system is an impairment of the conveyance and integrity of the canal systems as well as changing related streamflows and runoff. Land subsidence and differential land subsidence can affect elevations and slopes across the landscape, which can result in reduction in freeboard, reduced or reversed slopes, and even fractures in the canals. Similarly, the ability to convey natu- 


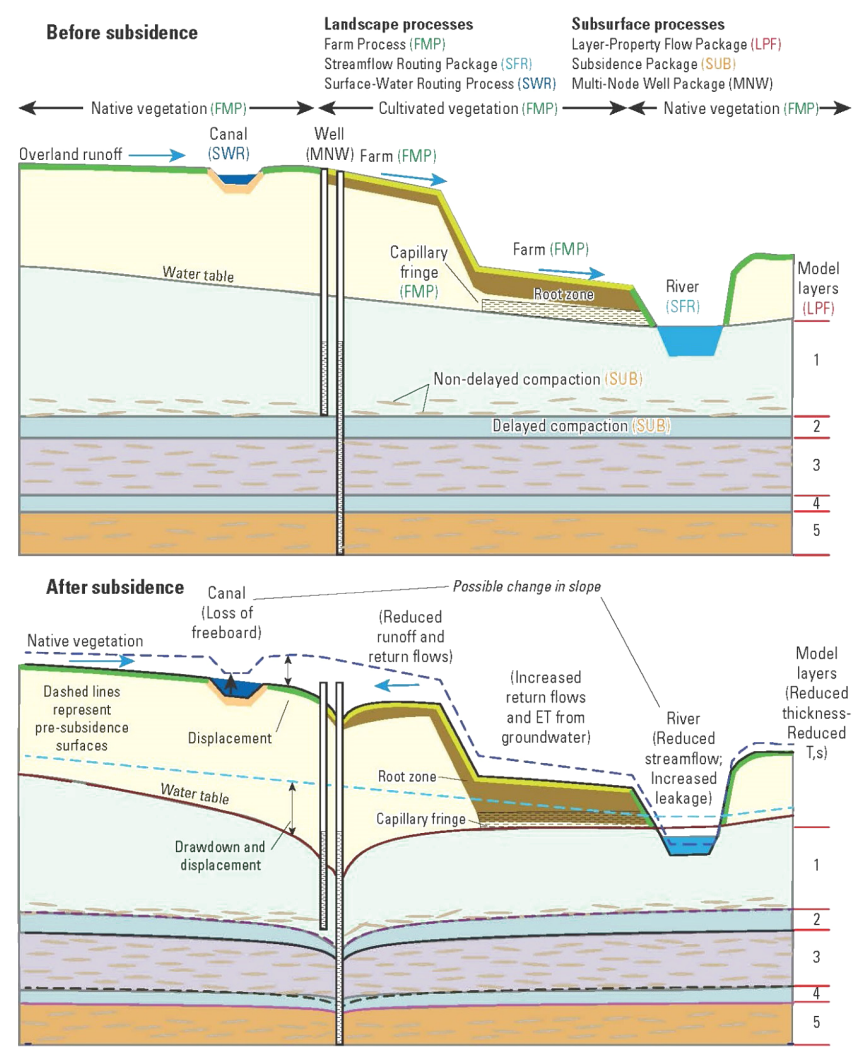

Figure 2. Diagram showing the relation between surface and subsurface processes with linkage to land subsidence (Schmid et al., 2014; Hanson et al., 2014).

ral streamflow, deliver water for irrigation, return landscape runoff to streams, or reuse such water is directly and indirectly affected by land subsidence. Finally, the effects of land subsidence are also occurring in the subsurface where compaction is releasing water from fine-grained interbed storage and, as a result, aquifer systems suffer reduced storage and transmission properties associated with the compaction.

MODFLOW (MF) uses a modular approach to represent surface processes that can interact with groundwater. In contrast to simulations that include only head-dependent flows, the assessment of conjunctive-use problems requires simulations with additional connectivity of flows of one stress term that directly depend on flows of other stress terms. For the analysis of deformation-dependent flows, a version of MODFLOW (MF) called MODFLOW-One Water Hydrologic Model (MF-OWHM, Hanson and Schmid, 2013) has been developed to include linkages between deformation, aquifer properties, and affected flow terms.

\section{Coupled land subsidence}

In MF-OWHM (Hanson et al., 2014), new linkages were provided for the Subsidence Package (SUB) (Hoffmann et al., 2003) with other packages and processes in a fully inte- grated hydrologic model, which calculate flow rates that are affected by the deformation of the land surface or hydrostratigraphic boundaries (Fig. 1). The new capability allows MF-OWHM to adjust elevations of the streambeds, canal and surface-water control-structure elevations, the land surface used by various agricultural, drain, and riparian evapotranspiration, and the tops and bottoms of aquifer layers. These changes also affect secondary calculations, such as the slope of a streambed, slope-related runoff in farms, proximity of the capillary fringe to the root zone, and changing hydraulic properties (transmissivity and storage coefficient) of aquifer layers (Fig. 2). The effects of these deformationdependent flows were first analyzed with respect to a hypothetical problem that had typical properties and features (Schmid et al., 2014). This analysis demonstrated significant effects from the direct feedback of deformation onto physical properties of the land surface and subsurface. The indirect feedback of deformation on conjunctive use is facilitated by connecting the effects of layer deformation and associated changed transmissivities to changes in groundwater, landscape, and surface water flows. These, in turn, may affect changes in surface-water and groundwater deliveries to farms. One might also consider a third level of feedback of changes of surface-water and groundwater deliveries back to further changes in subsidence. That is, for instance, a reduction in surface-water deliveries might contribute to increased groundwater pumping and thus increased subsidence.

A realistic hypothetical example (Fig. 1) was used to explore and demonstrate the effects of the subsidence linkage within a fully coupled hydrologic model (Schmid et al., 2014). The coupling also affects the differential deformation of each layer (Fig. 3a). The supply-and-demand timing and amount of surface water available for conjunctive use is affected within the valley, along the urban canal, and as an inflow to the downstream valley (Fig. 3b). Finally, the stage (and related freeboard) and flows in the urban canal are also adversely affected by land subsidence (Fig. $3 b$ ). There are reductions in outflow of as much as $8 \%$ during the summer months and a reduction in stage elevation in the urban canal of as much as $0.62 \mathrm{~m}$ that is potentially a reduction in freeboard simulated with the Surface Water Routing Process (SWR). The reductions in flows and stage affect the ability to deliver water through the urban canal and ultimately may also affect inter-basin transfers as deformation affects the integrity of the physical structures. The coupled deformation also affects water use and movement across the landscape related to irrigation and urban deliveries.

Substantial relative temporal and overall differences in streamflow occur at diversions to (Fig. 3c) and return flows (Fig. 3c) from farms that affect the amounts of surface water that is available to downstream farms for irrigation. There are also increased deliveries and reduced return flows during periods of subsidence. Thus, the amounts and sources of irrigation water are altered and the amount of water that is potentially divertible again for downstream farms is affected. 

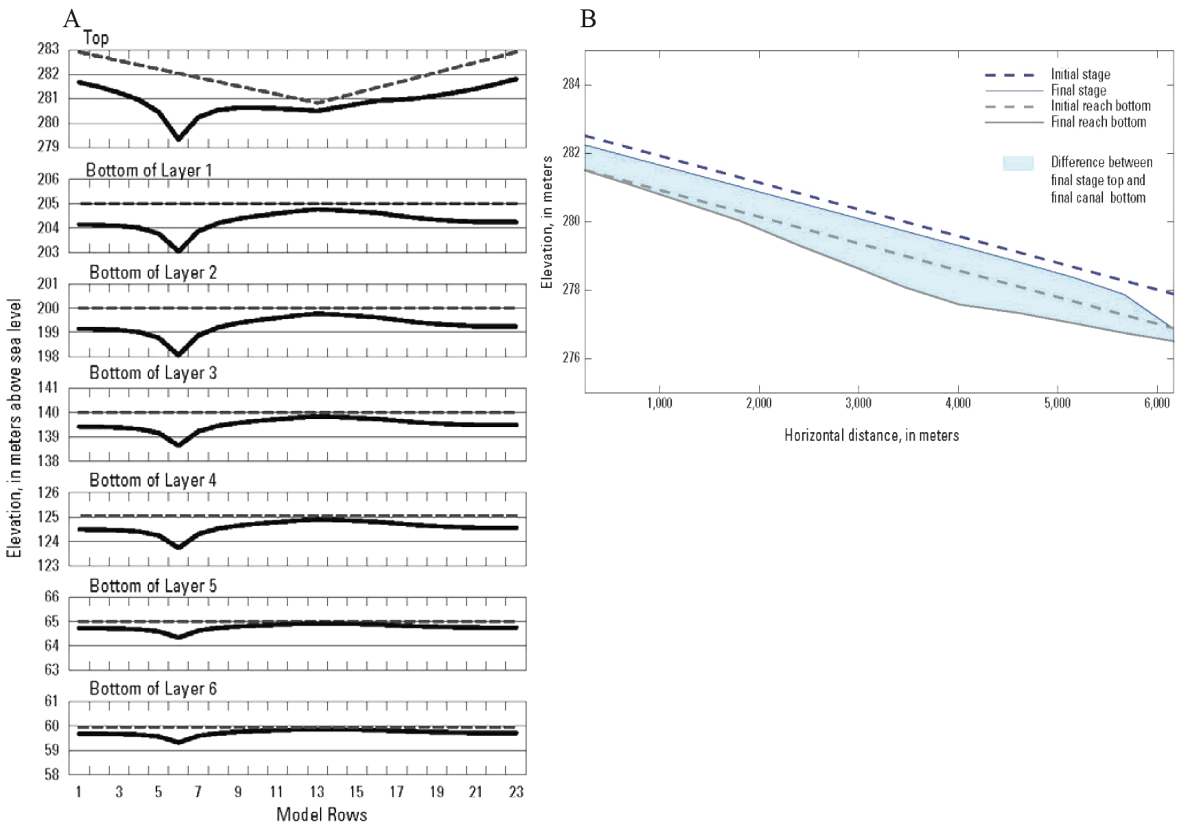

C

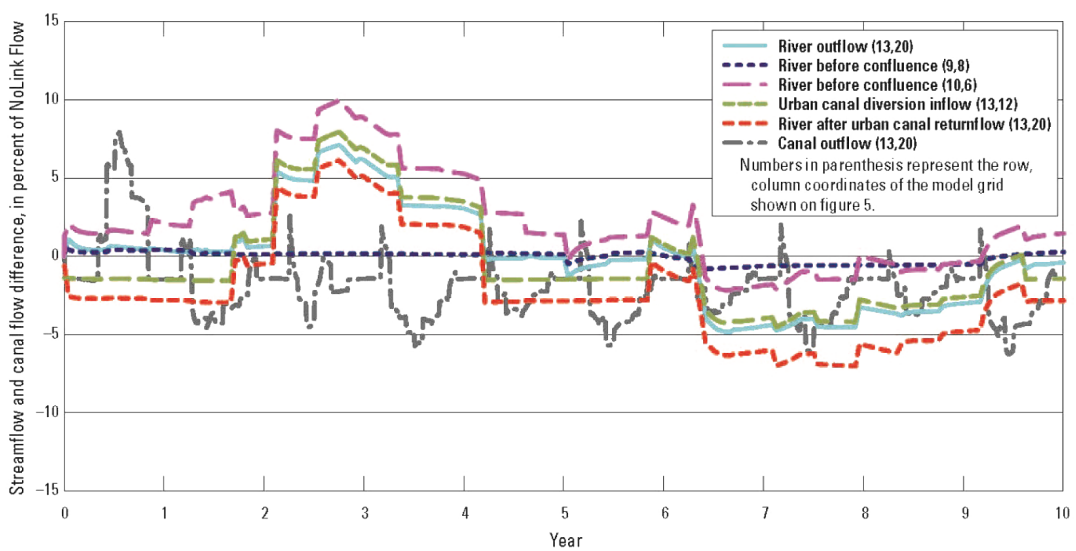

Figure 3. Example of simulated changes in bed altitudes (a) along model column 17 showing the final displacement of land surface and layer bottoms using SUB-Link (dashed line initial surface and solid line final surface), (b) with the deformable mesh using the Surface-water Routing Process of MF-OWHM along the urban canal, and (c) Difference in streamflow between using SUB-Link and using just SUB with no linkage (Schmid et al., 2014).

A real world example is under development for the Central Valley of California, where deformation of Delta Mendota Canal will be simulated by using the updated and refined Central Valley Model (Faunt et al., 2011). Examples of this development suggest that there are significant effects on the gradient of the canal and the bottom elevation, as well as differential elevation along the canal.

\section{Summary and conclusions}

The vertical displacement of the land surface and modellayer tops and bottoms calculated by the MODFLOW Subsidence Package has been linked to other MODFLOW pack- ages and processes that are affected by the altitude and slope of the land surface as well as by the model layer thicknesses. In a model of a hypothetical aquifer system, these feedback effects of land surface and mesh deformation were found to be significant. The effects were large enough spatially and temporally to affect the supply-and-demand components of conjunctive water use. Thus, modeling deformationdependent flows and hydraulic properties may be necessary to investigate the rate limiting aspects of conjunctive water use for a variety of flows in subsidence prone regions. In addition, the modeled feedback of deformation-dependent flows resulted in increased or decreased supplies and reduced or increased groundwater pumpage. That is, in some regions 
changes in land surface could either enhance or impede the use and movement of water.

The effects of feedback onto the land surface and aquifers from mesh deformation with MF-OWHM flow terms were found to be significant when compared to simulations without the subsidence linkage. The inclusion of land subsidence resulted in an even larger difference when compared to simulations that did not consider land subsidence for a hypothetical alluvial aquifer that is subject to sustained agricultural and urban demand that drive related secondary effects such as land subsidence. Therefore, these linkages are best suited for evaluating conjunctive water use where the vertical displacements or differential displacements may affect the sources of water, the proportions of multiple sources of water, as well as their use and movement across the landscape, the performance of conveyance through canals and rivers across the landscape, and the flow to and from the aquifers. Future work will involve applying methods described here to a real-world model of the Central Valley of California, USA.

\section{References}

Faunt, C. C., Hanson, R. T., Belitz, K., Schmid, W., Predmore, S. P., Rewis, D. L., and McPherson, K. R.: Numerical model of the hydrologic landscape and groundwater flow in California's Central Valley (Chapter C), in: Groundwater Availability of the Central Valley Aquifer, edited by: Faunt, C. C., California, U.S. Geological Survey Professional Paper 1776, 121e212, 2009.

Faunt, C., Hanson, R., Martin, P., and Schmid, W.: Planned Updates and Refinements to the Central Valley Hydrologic Model with an Emphasis on Improving the Simulation of Land Subsidence in the San Joaquin Valley, World Environmental and Water Resources Congress 2011, 864e870, 2011.
Hanson, R. T. and Schmid, W.: Economic resilience through "OneWater" Management, U.S. Geological Survey Open-File Report 2013-1175, p. 2, 2013.

Hanson, R. T., Flint, L. E., Flint, A. L., Dettinger, M. D., Faunt, C. C., Cayan, D., and Schmid, W.: A method for physically based model analysis of conjunctive use in response to potential climate changes, Water Resour. Res., 48, 23, doi:10.1029/2011WR010774, 2012.

Hanson, R. T., Boyce, S. E., Schmid, W., Hughes, J. D., Mehl, S. M., Leake, S. A., Maddock III, T., and Niswonger, R. G.: MODFLOW-One-Water Hydrologic Flow Model (OWHM), U.S. Geological Survey Techniques and Methods 6-A51, p. 122 (http://pubs.usgs.gov/tm/tm6a51/) 2014.

Hoffmann, J., Leake, S. A., Galloway, D. L., and Wilson, A. M.: MODFLOW-2000 Groundwater Model-user Guide to the Subsidence and Aquifer-system Compaction (SUB) Package, U.S. Geological Survey Open-File Report, 03e233, 46 pp., 2003.

Schmid, W., Hanson, R. T., Hughes, J., Leake, S. A., and Niswonger, R.: Feedback of land subsidence on the movement and conjunctive use of water resources, Environ. Modell. Softw., 62, 253-270, 2014.

Sneed, M., Brandt, J., and Solt, M.: Land subsidence along the Delta-Mendota Canal in the northern part of the San Joaquin Valley, California, 2003-10, U.S. Geological Survey Scientific Investigations Report 2013-5142, p. 87, doi:10.3133/sir20135142, 2013.

UNESCO: United Nations Organization for Education, Science and Culture (UNESCO) Glossary, http://webworld.unesco.org/water/ ihp/db/glossary/glu/EN/GF0237EN.HTM (last access: 1 August 2014) 2010. 